\title{
Gender differences in blood lipids and the risk of ischemic stroke among the hypertensive adults in rural China
}

\author{
Xingang Zhang, Zhaoqing Sun, Xinzhong Zhang, Liqiang Zheng*, Shuangshuang Liu, Changlu Xu, \\ Jiajin Li, Fenfen Zhao, Jue Li ${ }^{*}$, Dayi Hu*, Yingxian Sun \\ Department of Cardiology, Shengjing Hospital of China Medical University, Shenyang, P. R. China, *Heart, Lung and Blood Vessel Center, \\ Tongji University, Shanghai, P. R. China
}

\begin{abstract}
Background: Though large epidemiological studies have not established associations between blood lipids and ischemic stroke, increasing evidences have suggested that lipidmodifying agents may reduce cerebrovascular events. Aims: To determine whether blood lipids are risk factors for ischemic stroke among hypertensive rural adults in China. Settings and Design: A cross-sectional survey was conducted during 2004-2006, which underwent cluster multistage sampling to a hypertensive resident group in the countryside of China. Materials and Methods: A total of 6,412 individuals (2,805 men, 3,607 women) with age $\geq 35$ years were included. At baseline, lifestyle and other factors were obtained and blood lipids were assessed at a central study laboratory. Ischemic stroke was defined according to the criteria established by the National Survey of Stroke and all cases were further classified into lacunar infarction and other ischemic strokes. Statistical Analysis: Univariable and multivariable logistic regression were used. Results: In the univariable logistic regression model, LDL cholesterol (LDLC) in men and total cholesterol (TC), LDLC and TC-to-HDL cholesterol (TC: HDLc ratio) in women were risk factors for other ischemic strokes, with OR 1.42 (95\% Cl, 1.16-1.75), 1.31 (95\% Cl, 1.11-1.55), 1.47 (95\% $\mathrm{Cl}, 1.16-1.88)$ and $1.67(95 \% \mathrm{Cl}, 1.28-2.14)$, respectively. After adjusting for independent variables, an increase in non-HDL cholesterol (non-HDLc) was associated with a significant increased risk of other ischemic strokes in women, with adjusted OR $1.45(95 \% \mathrm{Cl}, 1.08-1.93)$. Conclusions: LDLc was the common risk factor for ischemic stroke in men and women, whereas Non-HDLc, TC and TC: HDLC ratio levels were related to ischemic stroke as risk factors only in women.
\end{abstract}

Key words: Cholesterol, hypertension, lipids, rural population, stroke
Stroke has become one of the leading causes of death in China. ${ }^{[1,2]}$ Epidemiological studies on stroke in China have showed that ischemic stroke is more frequent. ${ }^{[3]}$ Although hypertension is the major risk factor for stroke, data from secondary prevention trials which have evaluated the role of statins in stroke risk lends support to a causal relationship between cholesterol and cerebrovascular disease. ${ }^{[4]}$ However, the role of blood cholesterol as a cause of stroke remains uncertain..$^{[5-7]}$

In this study, we aimed to assess whether non-HDL cholesterol (non-HDLc), LDL cholesterol (LDLc), total cholesterol (TC), HDL cholesterol (HDLc), triglycerides (TG) and the TC: HDLc ratios are risk factors for ischemic stroke among the hypertensive rural population in the Liaoning province of China.

\section{Materials and Methods}

\section{Study population}

The procedures followed were in accordance with ethical standards of the responsible committee on human experimentation of China Medical University and informed consent was obtained from the patients or their relatives. A cross-sectional survey was conducted from October 2004 to June 2006 in the Liaoning province of China. The study used a cluster multistage sampling method, which included samples from rural hypertensive individuals in the northern, southern, western, eastern and the central regions of Fuxin county in Liaoning province. Only one small town was selected from each region. Finally, 10 rural villages near each small town were randomly selected from different geographic areas. In total, five small towns from these regions and 50 rural villages were selected to a resident group of age $\geq 35$ years. A total of 7975 hypertensive individuals were selected from these sampling units in rural areas. A total 
of 6,412 people (2,805 men, 3,607 women) completed the survey and had a serum cholesterol measurement. The response rate was $80.4 \%$.

\section{Measurements}

The baseline surveys were conducted by local doctors with home visits method. During the interview and examination, doctors administered a standard questionnaire including questions related to the lifestyle factors. Data on demographic variables (age, sex), smoking status and use of alcohol were obtained through interview. Blood pressure (BP) was measured with a checked electronic sphygmomanometer (Omron). The $\mathrm{BP}$ was measured with subjects in the sitting position and the average of three measurements was recorded. Subjects were asked to fast for at least $12 \mathrm{~h}$ before blood collection. Blood samples were obtained from an antecubital vein into vacutainer tubes containing EDTA. Blood chemical analyses were performed at a central, certified laboratory. Blood lipids and fasting glucose were analyzed enzymatically on an Olympus AU640 autoanalyzer.

\section{Definitions}

According to JNC 7, hypertension was considered to be present if any of the following conditions were met: systolic blood pressure $\geq 140 \mathrm{mmHg}$, diastolic blood pressure $\geq 90 \mathrm{mmHg}$ or reported use of any antihypertensive medications for hypertension. ${ }^{[8]}$ Selfreported or family-reported stroke were obtained from a questionnaire and all participants who reported an incident of stroke were asked for their permission to review their medical records, including reports of brain imaging. Ischemic stroke was defined according to the criteria established by the National Survey of Stroke ${ }^{[9]}$ and all cases were further classified into lacunar infarction and other ischemic strokes (cases that couldn't be classified in that way were excluded from the analysis). Non-HDLc was calculated by subtracting HDLc from TC. Body mass index was calculated by the weight in kilograms divided by the square of the height in meters. Drinking status was assessed by alcohol consumption; alcohol consumption was defined as the weekly consumption of beer, wine and hard liquor converted into grams of alcohol. Current drinking was defined as alcohol consumption ( $\geq 8 \mathrm{~g} /$ week). Smoking was defined as people who smoked at least one cigarette every day and continued for at least one year. Smoking was assessed as a part of the questionnaire.

\section{Statistical analysis}

All data analyses were conducted by using SPSS 11.5 statistical software package. Baseline variables were expressed as mean \pm SD or \%, in men and women, respectively. Means for baseline characteristics were compared for cases and controls through the use of
Student's t test and a Chi-square test was used to examine ratio differences. The univariable and multiple logistic regression analyses were used to evaluate the association between blood lipids and ischemic stroke. To avoid the collinearity and make more sense, we have HDLc, non-HDLc and TG in the multivariable model, but presented univariable associations for TC, LDLc and TC: HDLc ratios levels. The adjusted odds ratio (OR) was presented together with a $95 \%$ confidence interval. For all comparisons, P-values $<0.05$ were considered statistically significant.

\section{Results}

\section{Basic characteristics of the study population}

The characteristics of the hypertensive individuals with and without ischemic stroke are shown in Table 1. All subjects were selected from the age group of 35 to 92 years. For men, age, SBP levels, DBP levels, current drinking status and LDLc levels were significantly different among lacunar infarction group, other ischemic stroke group and non-stroke group. For women, age, SBP levels, DBP levels, fasting plasma glucose levels (FPG), TC levels, LDLc levels, non-HDLc levels and TC: HDLC ratio levels were significantly different among the three groups.

\section{Association between blood lipids and Ischemic stroke}

As shown in Table 2, TC, LDLc and TC: HDLc ratio levels had no significant relationship with risk of lacunar infarction either in men or women by the univariable logistic regression model. However, LDLc in men and TC, LDLC and TC: HDLc ratio in women were significantly associated with other ischemic strokes. Table 3 presents risk factors of lacunar infarction and other ischemic strokes in men and women which are respectively, adjusted for age, smoker, drinker, BMI, SBP, DBP, FPG, HDLc, non-HDLc and TG. Increasing with TG, non-HDLc and HDLc, the risk of lacunar infarction had no significant increase or decrease in both genders. For women, an increase in non-HDLc was associated with a significant increased risk of other ischemic strokes, adjusted OR was $1.45(95 \% \mathrm{Cl}, 1.08-1.93)$. However, TG and HDLc had no significant relationship with risk of other ischemic strokes for both genders.

\section{Discussion}

The main finding of this study was that LDLc levels in men, whereas TC, LDLc, TC: HDLc ratio and non-HDLc levels in women were associated with other ischemic strokes. However, we didn't see a significant relationship between blood lipids and lacunar infarction either in men or women.

Although the role of blood lipids in coronary heart disease is well documented, it is still unclear whether the 
Table 1: Basic characteristics in rural hypertensive individuals with and without ischemic stroke

\begin{tabular}{|c|c|c|c|c|c|c|c|c|}
\hline \multirow[t]{2}{*}{ Characteristics } & \multicolumn{4}{|c|}{ Men } & \multicolumn{4}{|c|}{ Women } \\
\hline & $\begin{array}{l}\text { Lacunar } \\
\text { infarction }\end{array}$ & $\begin{array}{l}\text { Other ischemic } \\
\text { strokes }\end{array}$ & Non-stroke & $P$ value & $\begin{array}{l}\text { Lacunar } \\
\text { infarction }\end{array}$ & $\begin{array}{l}\text { Other ischemic } \\
\text { strokes }\end{array}$ & Non-stroke & $P$ value \\
\hline Participants (n) & 19 & 155 & 2619 & & 11 & 104 & 3463 & \\
\hline Age (year) & $63.58 \pm 9.15$ & $60.83 \pm 9.17$ & $57.54 \pm 11.48$ & $<0.01$ & $60.18 \pm 12.82$ & $61.52 \pm 8.84$ & $55.83 \pm 10.90$ & $<0.01$ \\
\hline $\mathrm{BMI}\left(\mathrm{kg} / \mathrm{m}^{2}\right)$ & $23.54 \pm 3.62$ & $23.42 \pm 3.01$ & $23.49 \pm 3.01$ & 0.96 & $23.02 \pm 4.00$ & $24.44 \pm 3.59$ & $24.23 \pm 3.73$ & 0.48 \\
\hline $\mathrm{SBP}(\mathrm{mmHg})$ & $158.21 \pm 18.83$ & $168.25 \pm 23.18$ & $158.61 \pm 20.21$ & $<0.01$ & $172.55 \pm 16.71$ & $171.33 \pm 21.25$ & $161.51 \pm 21.45$ & $<0.01$ \\
\hline $\mathrm{DBP}(\mathrm{mmHg})$ & $94.68 \pm 13.95$ & $98.68 \pm 13.64$ & $94.27 \pm 12.05$ & $<0.01$ & $98.64 \pm 9.30$ & $97.55 \pm 13.14$ & $94.08 \pm 12.14$ & $<0.01$ \\
\hline Current smoker (\%) & 63.2 & 61.9 & 65.3 & 0.68 & 18.2 & 19.2 & 20.8 & 0.91 \\
\hline Current drinker (\%) & 42.1 & 38.7 & 56.9 & $<0.01$ & - & 4.8 & 7.2 & 0.42 \\
\hline $\begin{array}{l}\text { Fasting plasma } \\
\text { Glucose (mmol/L) }\end{array}$ & $5.65 \pm 1.19$ & $5.75 \pm 1.56$ & $5.76 \pm 1.67$ & 0.96 & $5.98 \pm 1.13$ & $6.25 \pm 2.76$ & $5.74 \pm 1.93$ & 0.03 \\
\hline $\begin{array}{l}\text { Total cholesterol } \\
(\mathrm{mmol} / \mathrm{L})\end{array}$ & $5.07 \pm 0.93$ & $5.28 \pm 0.92$ & $5.19 \pm 1.06$ & 0.49 & $5.72 \pm 0.81$ & $5.65 \pm 1.08$ & $5.32 \pm 1.05$ & $<0.01$ \\
\hline Triglyceride (mmol/L) & $1.31 \pm 0.49$ & $1.68 \pm 0.97$ & $1.66 \pm 1.78$ & 0.66 & $2.07 \pm 1.48$ & $2.10 \pm 1.99$ & $1.79 \pm 1.36$ & 0.06 \\
\hline HDLc (mmol/L) & $1.30 \pm 0.29$ & $1.40 \pm 0.28$ & $1.42 \pm 0.33$ & 0.30 & $1.45 \pm 0.30$ & $1.45 \pm 0.29$ & $1.44 \pm 0.33$ & 0.99 \\
\hline LDLc (mmol/L) & $2.70 \pm 0.61$ & $2.93 \pm 0.66$ & $2.73 \pm 0.72$ & $<0.01$ & $3.07 \pm 0.49$ & $3.09 \pm 0.69$ & $2.87 \pm 0.73$ & $<0.01$ \\
\hline Non-HDLc & $3.77 \pm 0.86$ & $3.88 \pm 0.74$ & $3.77 \pm 0.87$ & 0.33 & $4.26 \pm 0.57$ & $4.20 \pm 0.99$ & $3.88 \pm 0.85$ & $<0.01$ \\
\hline $\begin{array}{l}\text { Ratio of total/HDL } \\
\text { Cholesterol }\end{array}$ & $3.95 \pm 0.50$ & $3.80 \pm 0.48$ & $3.73 \pm 0.62$ & 0.13 & $4.00 \pm 0.47$ & $3.98 \pm 0.86$ & $3.75 \pm 0.59$ & $<0.01$ \\
\hline
\end{tabular}

Data are Mean \pm SD or \%. BMI - Body mass index, SBP - Systolic blood pressure, DBP - Diastolic blood pressure, HDLc - HDL cholesterol; LDLc, LDL cholesterol, non-HDLc - Non-HDL cholesterol

Table 2: Total cholesterol, LDLc and ratio of total/HDL cholesterol associated with ischemic stroke from univariable logistic regression model

\begin{tabular}{|c|c|c|c|c|}
\hline \multirow[t]{2}{*}{ Variables } & \multicolumn{2}{|c|}{ Lacunar infarction } & \multicolumn{2}{|c|}{ Other ischemic strokes } \\
\hline & OR $(95 \% \mathrm{CI})$ & Dvalue & OR $(95 \% \mathrm{Cl})$ & $P$ value \\
\hline \multicolumn{5}{|l|}{ Men } \\
\hline Total cholesterol & $0.90(0.57-1.40)$ & 0.64 & $1.09(0.94-1.26)$ & 0.28 \\
\hline LDLc & $0.94(0.49-1.78)$ & 0.85 & $1.42(1.16-1.75)$ & $<0.01$ \\
\hline Ratio of total/HDL cholesterol & $1.50(0.89-2.54)$ & 0.13 & $1.19(0.93-1.51)$ & 0.17 \\
\hline \multicolumn{5}{|l|}{ Women } \\
\hline Total cholesterol & $1.37(0.84-2.52)$ & 0.21 & $1.31(1.11-1.55)$ & $<0.01$ \\
\hline LDLc & $1.42(0.68-2.97)$ & 0.35 & $1.47(1.16-1.88)$ & $<0.01$ \\
\hline Ratio of total/HDL cholesterol & $1.74(0.82-3.68)$ & 0.15 & $1.66(1.28-2.14)$ & $<0.01$ \\
\hline
\end{tabular}

OR - Odds ratio, $\mathrm{Cl}$ - Confidence interval, LDLc - LDL cholesterol

Table 3: Factors associated with ischemic stroke from multivariable logistic regression model

\begin{tabular}{|c|c|c|c|c|}
\hline \multirow[t]{2}{*}{ Variables } & \multicolumn{2}{|c|}{ Lacunar infarction } & \multicolumn{2}{|c|}{ Other ischemic strokes } \\
\hline & OR $(95 \% \mathrm{Cl})$ & $P$ value & OR $(95 \% \mathrm{Cl})$ & $P$ value \\
\hline \multicolumn{5}{|l|}{ Men } \\
\hline Age (years) & $1.05(1.01-1.10)$ & 0.03 & $1.02(1.00-1.04)$ & 0.02 \\
\hline BMI $\left(\mathrm{kg} / \mathrm{m}^{2}\right)$ & $1.05(0.90-1.21)$ & 0.56 & $0.99(0.94-1.05)$ & 0.75 \\
\hline $\mathrm{SBP}(\mathrm{mmHg})$ & $0.99(0.96-1.01)$ & 0.31 & $1.01(1.00-1.02)$ & 0.01 \\
\hline $\mathrm{DBP}(\mathrm{mmHg})$ & $1.02(0.99-1.07)$ & 0.32 & $1.02(1.01-1.04)$ & 0.01 \\
\hline Fasting plasma glucose (mmol/L) & $0.99(0.73-1.35)$ & 0.96 & $0.97(0.87-1.07)$ & 0.51 \\
\hline Smoking status & $1.28(0.46-3.53)$ & 0.64 & $1.22(0.85-1.77)$ & 0.28 \\
\hline Drinking status & $0.62(0.22-1.71)$ & 0.36 & $0.47(0.32-0.68)$ & $<0.01$ \\
\hline $\mathrm{HDLc}(\mathrm{mmol} / \mathrm{L})$ & $0.17(0.03-1.07)$ & 0.06 & $0.69(0.37-1.27)$ & 0.23 \\
\hline Non-HDLc (mmol/L) & $1.55(0.88-2.71)$ & 0.13 & $1.26(1.00-1.58)$ & 0.05 \\
\hline Triglyceride (mmol/L) & $0.71(0.40-1.28)$ & 0.26 & $1.00(0.89-1.11)$ & 0.93 \\
\hline \multicolumn{5}{|l|}{ Women } \\
\hline Age (years) & $1.03(0.96-1.09)$ & 0.44 & $1.05(1.03-1.07)$ & $<0.01$ \\
\hline BMI $(\mathrm{kg} / \mathrm{m} 2)$ & $0.89(0.73-1.08)$ & 0.24 & $1.02(0.97-1.07)$ & 0.43 \\
\hline $\mathrm{SBP}(\mathrm{mmHg})$ & $1.01(0.98-1.04)$ & 0.51 & $1.01(1.00-1.02)$ & 0.13 \\
\hline $\mathrm{DBP}(\mathrm{mmHg})$ & $1.02(0.97-1.08)$ & 0.38 & $1.02(1.00-1.04)$ & 0.03 \\
\hline Fasting plasma glucose (mmol/L) & $1.02(0.78-1.33)$ & 0.90 & $1.05(0.98-1.13)$ & 0.15 \\
\hline Smoking status & $0.83(0.17-3.93)$ & 0.81 & $0.82(0.49-1.39)$ & 0.46 \\
\hline Drinking status & - & - & $0.75(0.29-1.93)$ & 0.54 \\
\hline $\mathrm{HDLc}(\mathrm{mmol} / \mathrm{L})$ & $0.41(0.04-3.92)$ & 0.44 & $0.48(0.22-1.02)$ & 0.06 \\
\hline Non-HDLc (mmol/L) & $1.76(0.78-3.98)$ & 0.18 & $1.45(1.08-1.93)$ & 0.01 \\
\hline Triglyceride (mmol/L) & $0.96(0.63-1.45)$ & 0.83 & $0.98(0.85-1.13)$ & 0.78 \\
\hline
\end{tabular}

OR - Odds ratio; CI - Confidence interval; BMI - Body mass index; SBP - Systolic blood pressure; DBP - Diastolic blood pressure; HDLc - HDL cholesterol; non-HDLC - non-HDL cholesterol. Adjusted for age, BMI, SBP, DBP, fasting plasma glucose, smoking status, drinking status, HDLc, non-HDLc and triglyceride 
lipid profile plays an important etiologic role in ischemic stroke. Previous studies of stroke risk in relation to TC have been inconclusive. The EUROSTROKE project could not show an association of TC with ischemic stroke, ${ }^{[10]}$ whereas in an observational study of subjects with coronary heart disease, TC levels were associated with risk of ischemic stroke (RR, $1.43 ; 95 \% \mathrm{Cl}, 1.20$ to 1.70$).{ }^{[11]}$ Another study found that there was no significant relationship with risk of ischemic stroke across quartiles (OR, 1.56; $95 \% \mathrm{Cl}, 0.84$ to 2.92$){ }^{\left[{ }^{[12]}\right.} \mathrm{In}$ our study, we disclose a significant association between TC levels and risk of ischemic stroke in women (OR, $1.31 ; 95 \% \mathrm{Cl}, 1.11$ to 1.55). Because of the inconsistent observational data, further studies are needed to confirm this relationship.

LDLc is the major atherogenic lipoprotein ${ }^{[13]}$ and results of clinical trials of LDLc lowering with statins have demonstrated reduction in ischemic strokes. One study has found that statins may provide benefits for the long-term functional outcome when administered before the onset of cerebral ischemia. ${ }^{[14]}$ In the Heart Protection Study, statins reduced $4.0 \%$ of the ischemic stroke. ${ }^{[15]}$ The Anglo-Scandinavian Cardiac Outcomes Trial-Lipid-Lowering Arm (ASCOT-LLA) study found that statins reduced $27 \%$ of fatal and non-fatal stroke. ${ }^{[16]}$ Clinical trials with statins have possibly indicated a lipid mechanism to stroke, despite these HMG-CoA reductase inhibitors may have other effects such as interfering with platelet aggregation, antioxidative, improving blood flow to the ischemic brain. ${ }^{[17,18]}$ In this study, LDLc was significantly associated with other ischemic stroke and the results might support the lipid mechanism to stroke.

The Framingham Heart Study ${ }^{[19]}$ found that the TC: HDLc ratio was a superior measure of risk for coronary heart disease (CHD); the TC: HDLc ratio has been widely studied in association with CHD. ${ }^{[20]}$ But the data on the association between TC: HDLc ratio and ischemic stroke were few. A prospective cohort study in women found that TC: HDLc ratio was significantly associated with increased risk of ischemic stroke. ${ }^{[21]}$ In our study, results were consistent with the possibility that the TC: HDLc ratio was significantly associated with ischemic stroke in women.

Although the evidences suggests the inverse relation of HDLc and the risk of ischemic stroke, ${ }^{[22]}$ the association between HDLc and ischemic stroke is still unclear. The ARIC study found that in women there were some suggestions of a lower risk of ischemic stroke with increasing HDLc within the top quartile, especially above its median $(1.99 \mathrm{mmol} / \mathrm{L}, 77 \mathrm{mg} / \mathrm{dL})$, however, that was not significant in men. ${ }^{[23]}$ Another study found that, after adjustment, HDLc levels were not significantly associated with ischemic stroke risk, compared with the reference lowest quartile, the highest quartile of HDLc had an adjusted OR of $0.75(95 \% \mathrm{Cl}, 0.43$ to 1.30$) .^{[12]}$

Data on the association between serum TG and stroke have been conflicting. Several studies have found an association between high triglycerides and ischemic stroke. ${ }^{[24]}$ In the Bezafibrate Infarction Prevention (BIP) study, after adjusted for traditional risk factors, TG > $200 \mathrm{mg} / \mathrm{dL}$ were associated with an OR for ischemic stroke of $1.47(95 \% \mathrm{Cl}, 1.19$ to 1.80$)$ compared with lower TG levels. ${ }^{[25]}$ Other studies reported no association between TG and ischemic stroke. ${ }^{[12,26-28]}$

The strength of the present study is that we analyzed non-HDLc for ischemic stroke from population-based data, which was proposed as a risk marker for coronary heart disease and as a secondary target of therapy. ${ }^{[13]}$ However, there were spare data about non-HDLc and stroke. In the Strong Heart Study, increasing with nonHDLc the risk of stroke had not increased significantly. ${ }^{[29]}$ Another study found that the multivariable-adjusted hazard ratio of ischemic stroke was $2.45(95 \% \mathrm{Cl}, 1.54$ to 3.91) for non-HDLc. ${ }^{[21]}$ Our study found that there was a significant increase of ischemic stroke with the increase of non-HDLc levels in women $(\mathrm{OR}, 1.45 ; 95 \% \mathrm{Cl}, 1.08$ to 1.93). Although results from different studies were completely different, we suggested that non-HDLc may be useful in predicting ischemic stroke risk.

Our study has some limitations. Firstly, this is a cross-sectional design, which reflects only associations between blood lipids and risk factors, but is unable to observe prospectively. Secondly, the self-reported method could increase the potential for misclassification of stroke. This may have led to an overestimation or underestimation of the impact of various risk factors by stroke subtype. Thirdly, although this is a populationbased study with a large sample size, the estimation may not exactly represent the entire population of Liaoning, hence the findings limit generalizability. Moreover, China is a vast country with diverse lifestyles. Our findings cannot be extrapolated to other provinces in the country. Fourthly, in this study, the sample contains only hypertensives and lacks normotensives to compare. Additionally, lacunar infarction may have missed being diagnosed because the rural population couldn't afford medical treatment. Other limitations include recall bias and confounding factors.

\section{Conclusion}

Our study was a large-sample investigation in the rural hypertensive population and we found that there were some gender differences in the relationship between blood lipids and ischemic stroke. This study also suggested that TC: HDLc ratio and non-HDLc might be more useful predictive risk factors for ischemic stroke in women. However, more studies will be required to evaluate the validity of our results. 


\section{Acknowledgement}

This study was supported by Grants from the key technology Research and Development program of Liaoning Province (2003225003).

\section{References}

1. Wu ZS, H ong ZG, Yao CH, Chen DY, L i N, Zhang M, etal. Sino-M ON ICA-B eijing study: Report of the results between 1983-1985. Chin M ed J (Engl) 1987;100:611-20.

2. L i S, Schoenberg BS, Wang C, Cheng X, B olis CL, Wang K. Cerebrovascular disease in the People's Republic of China: E pidemiologic and clinical features. N eurology 1985;35:1708-13.

3. Zhang L F, Yang J , H ong Z, Yuan GG, Zhou B F, Zhao L C, e al. Proportion of different subtypes of stroke in China. Stroke 2003;34:2091-6.

4. Goldstein L B, Adams R, B ecker K, Furberg CD, Gorelick PB, H ademenos $G$, \& al. Primary prevention of ischemic stroke: $A$ statement for healthcare professionals from the Stroke Council of the A merican $\mathrm{H}$ eart Association. Circulation 2001;103:163-82.

5. Ariesen MJ, Claus SP, Rinkel GJ , Algra A. Risk factors for intracerebral hemorrhage in the general population: A systematic review. Stroke 2003;34:2060-5.

6. Cholesterol, diastolic blood pressureand stroke: 13,000 strokes in 450,000 people in 45 prospective cohorts. Prospective Studies Collaboration. L ancet 1995;346:1647-53.

7. $\mathrm{H}$ art $\mathrm{CL}, \mathrm{H}$ ole DJ , Smith GD. R isk factors and 20-year stroke mortality in men and women in the Renfrew/Paisley study in Scotland. Stroke 1999;30:1999-2007.

8. Chobanian AV, B akris GL, B lack H R, Cushman WC, Green LA, I zzo J L \& $a$ l. The seventh report of the joint national committee on prevention, detection, evaluation and treatment of high blood pressure: The J NC 7 report. J AMA 2003;289:2560-72.

9. Walker $A E$, R obins $M$, Weinfeld $F D$. The national survey of stroke: Clinical findings. Stroke 1981;12:113-44.

10. B ots ML, E lwood PC, N ikitin Y, Salonen J T, Freire de Concalves A, Inzitari D, \& al. Total and HDL cholesterol and risk of stroke. EU ROSTROKE : A collaborative study among research centers in $E$ urope. J E pidemiol Community $\mathrm{H}$ ealth 2002;56:i19-24

11. Koren-M orag N, Tanne D, Graff E, Goldbourt U. L ow and high-density lipoprotein cholesterol and ischemic cer ebrovascular disease. Arch I ntern Med 2002;162:993-9.

12. B owman TS, Sesso HD, Ma J , K urth T, Kase CS, Stampfer MJ , \& al. Cholesterol and the risk of ischemic stroke. Stroke 2003;34:2930-4.

13. N ational Cholesterol E ducation Program (NCE P) Expert Panel on Detection, E valuation and Treatment of $\mathrm{H}$ igh $\mathrm{B}$ lood Cholesterol in Adults (Adult Treatment Panel III). Third Report of the $\mathrm{N}$ ational Cholesterol $E$ ducation Program (N CE P) E xpert Panel on D etection, E valuation and Treatment of $\mathrm{H}$ igh $\mathrm{B}$ lood Cholesterol in Adults (Adult Treatment Panel III) final report. Circulation 2002;106:3143-421.

14. Marti-Fabregas J , Gomis M, Arboix A, Aleu A, Pagonabarraga J , B elvis
$R$, etal. Favorable outcome of ischemic stroke in patients pretreated with statins. Stroke 2004;35:1117-21.

15. H eart Protection Study Collaborative Group. M R C/B H F H eart P rotection Study of cholesterol lowering with simvastatin in 20,536 high-risk individuals: A randomized placebo-controlled trial. $L$ ancet 2002;360:7-22.

16. Sever PS, D ahlof B, Poulter NR, Wedel $H, B$ eevers $G$, Caulfield $M$, $\notin$ al. P revention of coronary and stroke events with atorvastatin in hypertensive patients who have average or lower-than-average cholesterol concentrations, in the Anglo-Scandinavian Cardiac Outcomes Trial-L ipid L owering Arm (ASCOT-L LA): A multicentre randomized controlled trial. L ancet 2003;361:1149-58.

17. Vaughan CJ , D elanty N. N europrotective properties of statins in cerebra ischemia and stroke. Stroke 1999;30:1969-73.

18. Rosenson RS. B iological basis for statin therapy in stroke prevention. Curr Opin N eurol 2000;13:57-62.

19. K inosian B, Glick H, Garland G. Cholesterol and coronary heart disease: Predicting risks by levels and ratios. Ann Inter M ed 1994;121:641-7.

20. Criqui $\mathrm{MH}, \mathrm{Golomb} B \mathrm{~B}$. E pidemiologic aspects of lipid abnormalities. Am J Med 1998;105:48S-57S

21. Kurth T, Everett B M, B uring J E, K ase CS, Ridker PM, Gaziano $\mathrm{J} M$. L ipid levels and the risk of ischemic stroke in women. N eurology 2007;68:556-62.

22. L indenstrom $E, B$ oysen $G, N$ yboe J . Influence of total cholesterol, high density lipoprotein cholesterol and triglycerides on risk of cerebrovascular disease: The Copenhagen City H eart Study. B MJ 1994;309:11-5.

23. Shahar E, Chambless LE, Rosamond WD, B oland LL, B allantyne $C M, M C G o v e r n P G, \&$ al. Plasma lipid profile and incident ischemic stroke: The Atherosclerosis R isk in Communities (ARIC) Study. Stroke 2003;34:623-31.

24. $H$ achinski V, Graffagnino C, B eaudry M, B ernier G, B uck C, D onner A, e al. Lipids and stroke: A paradox resolved. Arch N eurol 1996;53:303-8.

25. Tanne D, Koren-Morag N, Graff E, Goldbourt U. Blood lipids and first-ever ischemic stroke/transient ischemic attack in the bezafibrate infarction prevention (BIP) Registry: $\mathrm{H}$ igh triglycerides constitute an independent risk factor. Circulation 2001;104:2892-7.

26. Pedro-B otet J, Senti M, Nogues X, Rubies-Prat J, Roquer J $D$ 'Olhaberriague $L, \notin$ al. $L$ ipoprotein and apolipoprotein profile in men with ischemic stroke. R ole of lipoprotein(a), triglyceride-rich lipoproteins, and apolipoprotein E polymorphism. Stroke 1992;23:1556-62.

27. Simons $L A, M C C$ allum J , Friedlander $Y$, Simons J . Risk factors for ischemic stroke: Dubbo study of the elderly. Stroke 1998;29:1341-6.

28. Wannamethee SG, Shaper AG, E brahim S. HDL-cholesterol, total cholesterol and the risk of stroke in middle- aged British men. Stroke 2000;31:1882-8.

29. $L u$ W, Resnick $H E$, J ablonski $K A$, J ones $K L$, J ain $A K, H$ oward WJ , $€$ al. N on-H DL cholesterol as a predictor of cardiovascular disease in type 2 diabetes: The strong heart study. Diabetes Care 2003;26:16-23.

Accepted on 21-06-2007

Source of Support: Grants from the key technology Research and Development program of Liaoning Province (2003225003), Conflict of Interest: None declared. 